\title{
Managing and organising collaborative improvement: a system integrator perspective
}

\section{Rick Middel* and Olaf Fisscher}

Department of Operation, Organization and Human Resources

School of Business, Public Administration and Technology

University of Twente

P.O. Box 217, Enschede, The Netherlands

E-mail: h.g.a.middel@bbt.utwente.nl

E-mail: o.a.m.fisscher@bbt.utwente.nl

*Corresponding author

\section{Aard Groen}

NIKOS, Dutch Institute for Knowledge Intensive Entrepreneurship and Department of Strategic Market Oriented and International Management

School of Business, Public Administration and Technology

University of Twente

P.O. Box 217, Enschede, The Netherlands

E-mail: a.j.groen@bbt.utwente.nl

\begin{abstract}
More than ever, companies are challenged to improve their performance and respond quickly and accurately to changes within the market. Because of external dynamics, competition is moving towards the level of networks of organisations, and thus the individual firm is an inadequate entity for identifying improvements. The concept of continuous improvement must be applied and used in inter-organisational settings, leading to the concept of collaborative improvement. In order to gain an insight and develop knowledge of the process of collaborative improvement from a system integrator perspective, we use the network model of actors. This paper will discuss some empirical findings on the scope, scale, skill and value, and social networking of collaborative improvement as part of the network model.
\end{abstract}

Keywords: Collaborative Improvement (CoI); Continuous Improvement (CI); action research; System Integrator (SI); network model.

Reference to this paper should be made as follows: Middel, R., Fisscher, O. and Groen, A. (xxxx) 'Managing and organising collaborative improvement: a system integrator perspective', Int. J. Technology Management, Vol. X, No. Y, pp.000-000.

Biographical notes: Ir. Rick Middel is a $\mathrm{PhD}$ student at the Faculty of Business, Public Administration and Technology at the University of Twente. He studied Industrial Engineering and Management at the University of Twente (NL). From 2002 to 2003, he was a Research Assistant at the Department of Technology and Organisation at the University of Twente (NL). His research interests include continuous improvement, collaborative improvement, action learning, and action research. 
Professor Dr.Ir. Olaf A.M. Fisscher holds a Master's degree in Industrial Engineering Management. He obtained his $\mathrm{PhD}$ in Social Sciences at the University of Groningen in 1986 on the management and organisation of $\mathrm{R} \& \mathrm{D}$ laboratories. His research interests include organising for innovation and organising for corporate social responsibility. Currently, he is Professor of Organization Studies and Business Ethics at the School of Business, Public Administration and Technology at the University of Twente.

Dr. Aard J. Groen is Director of NIKOS, the Dutch Institute for Knowledge Intensive Entrepreneurship, at the University of Twente. His research is focused on knowledge-intensive entrepreneurship in networks, studied by using a social system theoretical perspective. He chairs the High-Tech Small Form conference bi-annually in Enschede, and is a member of several entrepreneurship committees including the European Foundation for Management Development, the European Consortium of Innovative Universities and the Baltic Entrepreneurship Partnership. He received his Master's in Public Administration from the University of Twente, and his $\mathrm{PhD}$ in Business Administration from the University of Groningen. Groen has published several articles, books and chapters on innovation and entrepreneurship.

\section{Introduction}

More than ever, companies are challenged to improve their performance and respond quickly and accurately to changes within the market. Because of external dynamics, competition is moving towards the level of networks of organisations, and consequently the individual firm is an inadequate entity for identifying improvements. As companies adapt themselves according to market changes and competition, they increasingly link their internal processes with external customers and suppliers (Frohlich and Westbrook, 2001) in order to stay competitive. Consequently, new approaches must be developed to enhance business performance; in particular, there has to be continuous improvement in the performance between partners in a network of organisations (Kaltoft et al., 2003; Middel et al., 2005a).

Continuous Improvement (CI) is a consolidated concept in managerial theory and practice and is seen as vital in today's business environments, but a strong limitation of $\mathrm{CI}$ is that it is mainly dealt with in the context of stand-alone companies (Middel et al., 2005b). Here, the concept of CI must be applied and used in inter-organisational settings (Boer et al., 2000; Rijnders, 2002), however, there is still a substantial lack of empirically grounded contributions or theories on the concept of CI in an inter-organisational setting. The conventional concept of CI can hardly be applied in inter-organisational settings due to organisational, geographical and time-related barriers, and therefore needs to be transferred and extended to the level of collaborative continuous improvement, leading to the concept of Collaborative Improvement (CoI). The effectiveness of managing and organising any process, including that of $\mathrm{CI}$ and $\mathrm{CoI}$, depends a great deal on deep knowledge and understanding of that process (Boer and Gertsen, 2003). The objective of this paper is to gain an insight and develop an understanding of the organisation and management of CoI processes from a system integrator perspective. 
In this paper, we report a number of practical results over a period of one-and-a-half years based on a Dutch System Integrator in the automotive industry as part of the three-year EU research project CO-IMPROVE (Collaborative Improvement Tools for the Extended Manufacturing Enterprise (EME), G1RD - CT2000 - 00299). An action research approach was adopted to address the companies' improvement needs while creating knowledge and in-depth understanding of the process itself at the same time (Middel et al., 2006). This research took place in an inter-organisational setting involving a system integrator and three of its suppliers in The Netherlands.

The paper is structured as follows. First, we discuss the literature on CI in relation to the topic and scope of this paper. This section explains the starting point of the research and present the differences between $\mathrm{CI}$ and CoI. In order to gain insight and develop an understanding of CoI processes, we discuss the network model of actors to explain how organisations manage and organise collaborative improvement processes. In the next section, we elaborate on the applied research methodology of action research and how this approach was adopted within the specific setting. We next describe the results of one-and-a-half years of research from the perspective of the System Integrator (SI), and finally, the last section reflects on and discusses the findings of the research and highlights challenges for future research.

\section{From Continuous Improvement (CI) to Collaborative Improvement (CoI)}

Incremental improvement, essentially in manufacturing, has been widely discussed in the literature on CI (see e.g., Imai, 1986; Bessant and Caffyn, 1997, Boer et al., 2000). $\mathrm{CI}$ is the "planned, organised and systematic process of ongoing, incremental and company-wide change of existing work practices aimed at improving company performance" (Boer et al., 2000). CI has its early accounts going back to pre-industrial revolution times and before scientific management was developed (Boer et al., 2000). The export of the concept from the USA to Japan and its development there; the influence of many other concepts, such as Quality Circles, Total Quality Management and Lean Production; the explicit attention of many authors to CI (Imai, 1986; Robinson, 1991; Bessant and Caffyn, 1997; Caffyn, 1998; De Lange-Ros, 1999); and the work of the CINet group resulted in the development, exchange and dissemination of practical and theoretical research in the field of CI. CI is now a consolidated concept in managerial theory and practice and is seen as vital in today's business environments.

In a literature review on CI, presented in De Lange-Ros (1999), existing literature on CI was categorised into three different types:

1 The first type of literature on CI can be typified as attention literature, which stresses the importance of incremental improvements. This literature shows the importance of incremental improvement and it directs attention to the subject.

2 A second type of literature is descriptive literature, which describes a large variety of techniques that are used in practice. The strong feature of this literature is that it describes the different practices of incremental improvements (De Lange-Ros, 1999).

3 A third type of literature is based on an examination of what is going on in practice and then tries to build a theory based on the descriptions and categorisations of practice and is typified by De Lange-Ros (1999) as theory-building literature. 
The review by De Lange-Ros (1999) was based on papers, articles and books with regard to CI published before 1997. In a more recent review, Boer and Gertsen (2003) formulated a couple of intriguing challenges and questions for future research in the area of CI. Two of the challenges provided us with a starting point for this research:

1 More processual research is needed, in the firm belief that the effectiveness of managing any process, including $\mathrm{CI}$, depends a great deal on deep knowledge and understanding of that process (Boer and Gertsen, 2003).

$2 \mathrm{CI}$ is no longer restricted to intra-firm processes but increasingly to inter-firm processes as well (Boer et al., 2000; Rijnders, 2002; Boer and Gertsen, 2003).

The concept of CI has to be transferred and applied to inter-firm processes of disparate companies within a network, leading to the concept of CoI. CoI is defined here as: $a$ purposeful inter-company process that focuses on continuous incremental innovation aimed at enhancing the overall performance of the disparate companies within a network. It is simultaneously concerned with bringing about change in the network of disparate companies, developing network capabilities towards collaboration, learning and improvement, and generating actionable knowledge on the process of collaborative improvement (see also Cagliano et al., 2005; Middel et al., 2005b; Middel and McNichols, 2006).

There is still a substantial lack of empirically grounded contributions and theories on the concept of $\mathrm{CI}$ in an inter-organisational setting; however, the process of applying and transferring CI to inter-organisational settings is fraught with intra- and inter-organisational change issues and work practices. Table 1 indicates additional key components in the areas of strategy, culture, infrastructure, process and tools compared to the key components of CI, as identified by Caffyn (1998). The authors realise that the list depicted in Table 1 is not complete and that there are additional key components, but the list gives some insight into the difficulties of applying and transferring CI to the interorganisational setting.

Table 1 Commonalities of, and differences between CI and CoI

\begin{tabular}{|c|c|c|}
\hline Area & Key components of CI & Additional key components to CoI \\
\hline \multirow[t]{6}{*}{ Strategy } & Clear strategic framework for CI & \multirow{2}{*}{$\begin{array}{l}\text { Shared goals and vision with regard } \\
\text { to CoI }\end{array}$} \\
\hline & Long-term goals and short-term targets & \\
\hline & $\begin{array}{l}\text { Communication of CI strategy to all } \\
\text { employees }\end{array}$ & $\begin{array}{l}\text { Mutual understanding of CoI strategy } \\
\text { of all the companies }\end{array}$ \\
\hline & \multirow{3}{*}{$\begin{array}{l}\text { Top management commitment } \\
\text { Long-term, company-wide perspective }\end{array}$} & Company/EME commitment towards \\
\hline & & \\
\hline & & $\begin{array}{l}\text { Long-term optimisation instead of } \\
\text { short-term orientation }\end{array}$ \\
\hline \multirow[t]{4}{*}{ Culture } & $\begin{array}{l}\text { Shared belief in the value of small } \\
\text { improvements }\end{array}$ & $\begin{array}{l}\text { Shared belief in prosperity through } \\
\text { collaboration and improvement }\end{array}$ \\
\hline & \multirow{2}{*}{$\begin{array}{l}\text { Belief that all employees have creative } \\
\text { potential }\end{array}$} & Trust \\
\hline & & \multirow{2}{*}{$\begin{array}{l}\text { Openness is sharing information, } \\
\text { learning moments, and knowledge }\end{array}$} \\
\hline & Treating failure as a learning opportunity & \\
\hline
\end{tabular}

Source: Middel et al. (2005b) 
Table 1 Commonalities of and differences between CI and CoI (continued)

\begin{tabular}{lll}
\hline Area & Key components of CI & Additional key components to CoI \\
\hline Infrastructure & Flattened hierarchy & Effective communication channels \\
& Team working and flexibility & CI 'vehicles', such as \\
problem-solving groups or CI teams \\
Devolution of decision making and & Devolution of decision-making \\
empowerment & Commitment to exploiting and \\
& Effective communication channels & exploring improvement potential \\
& Commitment to training and personnel & inside collaborative relationships \\
& development & \\
& CI facilitators & \\
& CI 'vehicles', such as problem-solving & \\
groups or CI teams & \\
Process & Formal CI/problem-solving cycle & Capture and transfer of learning \\
& Capture and transfer of learning & between and within companies \\
& Recognition and reward of CI activity & Benefit sharing \\
Tools & Company 'toolbox' with a range of & EME 'toolbox' with a range of CoI \\
& CI tools & tools that are applied similarly within \\
& 'Toolbox manager' & the EME companies \\
\hline
\end{tabular}

Source: Middel et al. (2005b)

In order for companies to be able to organise and manage the process of collaborative improvement in an inter-organisational setting, they need to gain insight and develop understanding and knowledge of the process itself. This is in line with the advocacy for more processual research by Boer and Gertsen (2003).

\section{Research issue}

Many firms operate within networks, collaborating with other companies to deliver final products to the market. The basic mechanism that characterises these kinds of network relations is collaboration. Collaboration between companies consists of working together, over an extended period of time, for the benefit of both (Ring and Van de Ven, 1992). Collaboration brings about the idea of interdependence between actors, shared goals and vision, information and technology exchange, joint work and activities (Lamming, 1993; Mohr and Spekman, 1994).

Networks are often defined as patterned relationships between actors, such as individuals, groups and organisations (Aldrich and Zimmer, 1986; Burt, 1992), while others define networks as a set of interdependent actors, activities and resources (Håkansson and Snehota, 1995). As such, the network is a social construction and is built upon social relationships among actors (Håkansson, 1987). The interest in the topic of networks is concentrated on the way in which organisations manage and organise the collaborative improvement process.

Sobrero and Schrader (1998) suggest that there are two dimensions, which are 'fundamental' to the management of inter-firm relationships: contractual and procedural coordination. Since the key to CI is development and learning (Boer et al., 2000), we want to focus on the procedural coordination, which is necessary for the exchange of information and organisational learning (Burns and Stalker, 1961; Nonaka and Takeuchi, 
1995). Doz et al. (1989) state that actual coordination is achieved not through contractual means but by patterns of communication involving individual employees: 'Top management puts together strategic alliances and sets the legal parameters for exchange. But what actually gets traded is determined by day-to-day interactions of engineers, marketers, and product developers'.

In order to analyse the process of collaborative improvement within an inter-organisational setting, we assume that actors act purposefully in interaction in collaborative improvement process with other actors (Granovetter, 1992). As such, each actor within this process is embedded in a socio-economic environment in a social and structural way (see Granovetter, 1992). We will use the network model of actors in a social system perspective (see Figure 1). Based on this framework, each actor has four mechanisms that can be used more or less successfully in the process of collaborative improvement, namely, striving for goal attainment (Scope), optimisation of processes (Scale), maintaining patterns of culturally structured and shared symbols (Skill), and interaction among actors (Social Networking) (see Groen et al., 2002). All four mechanisms work concurrently and influence the process and progress of the collaborative improvement process. As explained by Groen et al. (2002), one of the basic hypotheses in social system theory is that, only when all four mechanisms are developed sufficiently, can a social system last. Actors develop a structure of collaborative improvement based on actions and usage of the mechanisms in interaction with other actors. We describe how the SI has used scope, scale, skill and social networking more or less successfully in the process of collaborative improvement and so has developed a structure for collaborative improvement. Throughout the process, there has been an explicit focus on evaluation and reflection of collaborative improvement processes with, and between the involved companies, and the results were especially reflected against the $4 \mathrm{~S}$ framework.

Figure 1 Network model of actors

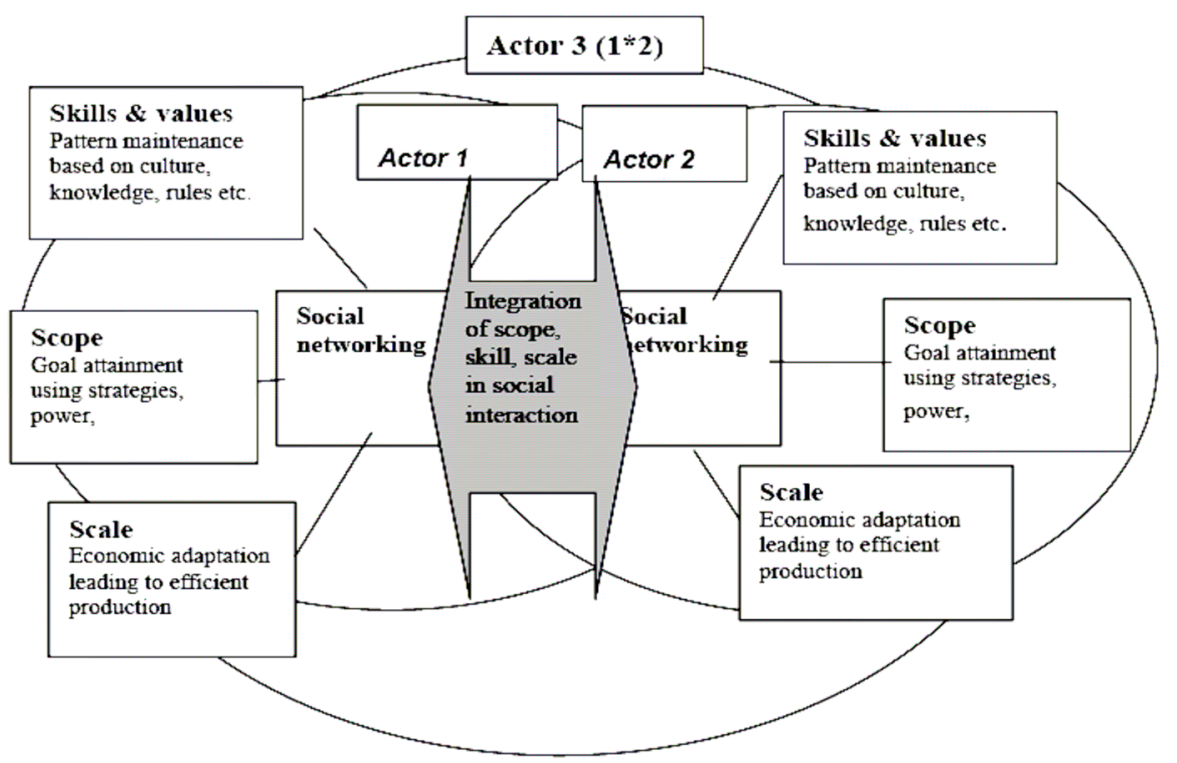

Source: Groen et al. (2002) 


\section{Methodology}

In order to be able to manage and organise the process of CoI effectively, managers need to develop an understanding of, and create insight into the process itself. Accordingly, not only managers, but also researchers, are encouraged to use and apply approaches, methods and techniques that address the needs and concerns of both applied action towards improvement and creating knowledge and in-depth understanding of the process. An approach that addresses the two issues of taking action and creating knowledge is Action Research (AR) (Westbrook, 1995; Coughlan and Coghlan, 2002). Action research is a cyclical process of diagnosing, action planning, action taking, evaluating and specifying learning (Lau, 1999). Action research focuses on research in action, rather than research about action, in which members of the studied system actively participate in the cyclical process. Several broad characteristics define action research (Eden and Huxman, 1996; Coghlan and Brannick, 2005; Coughlan and Coghlan, 2002):

- research in action, rather than research about action

- participative

- concurrent with action

- a sequence of events and an approach to problem-solving.

The research was undertaken through an AR approach where the researchers were both managing the project and studying it at the same time (Coghlan and Brannick, 2005; Coughlan and Coghlan, 2002). This research engaged in significant work as it explored the experience of learning-in-action and so an opportunity for AR (Coughlan et al., 2004). As stated by Westbrook (1995), a main contribution of action research to learning, which is not available to other methods, is that when participants involve themselves in change experiments, they engage in non-trivial learning and they think and reflect seriously on what they are doing.

The AR approach is adopted to facilitate and to stimulate the development of a capability for improvement and learning process within the EME. The AR approach was adopted in the EME over a period of 18 months through a cycle of 15 workshops. These workshops were organised on a monthly basis. The workshops were aimed at engaging companies in collaborative improvement activities, involving processes of diagnosing, fact-finding, implementation and evaluation of improvement actions. As the companies engaged themselves in $\mathrm{CoI}$ initiatives during and between the workshops, the action researchers faced the challenge of generating actionable knowledge on CoI. The action researchers wrote minutes and reflective notes of each workshop and documented results from assignments, reflected upon the documents offline and fed the information back to the companies within the EME during the workshops. Each workshop was preceded and followed by a meeting among the action researchers. In this way, the action researchers were able to understand the generated data, expose and test their assumptions and interpretations, and reflect and analyse upon the issues to generate actionable knowledge on CoI. 


\section{Research base}

This section reports on the context of the research by introducing the Dutch network: one system integrator and three of its first-tier suppliers. The SI is a company that specialises in 'Motion Control'-systems for different markets, such as the automotive, truck, marine, medical and agriculture market. The company sees itself in a niche market, predominantly automotive and truck. The competition is known and it is intense with a main emphasis on price. The company observes a shift in the market towards a commodity market. In this new market, the order-winning criterion is price whereas quality and technology are qualifiers. For a company in the automotive industry nowadays, a main challenge is to constantly monitor the cost-structure in order to remain profitable. Recently, price pressure from the Original Equipment Manufacturers (OEM) has led to an increase in prices of raw materials and contracts on long-term delivery schedules. Therefore, the company has mounted a strategic objective to produce zero-defect products together with the lowest total cost from world-class suppliers to satisfy their requirements on quality, cost and delivery.

Continuous improvement and continuous cost reduction are integrated and explicit in the SIs policy and practices. The aim is to establish close cooperation and long-term agreements with a limited number of suppliers. As such, the SI looks for highly involved and dedicated partners that fully support the company in assembling and delivering to customers systems of top quality at agreed competitive prices and at the promised delivery date. The suppliers selected by the system integrator to participate in the project are in accordance with the aim of the SI and are perceived as strategically significant. Furthermore, they are highly involved in collaboration as dedicated partners that fully support the SI in assembling and delivering the systems of the SI. Next to that, all three suppliers represent different types of relationships and deliver different categories of products (see Table 2). This selection means that information and communication can pass freely throughout the whole group without running the risk of giving away (or transferring) sensitive information to competitors.

Table 2 Companies in the network

\begin{tabular}{|c|c|c|c|}
\hline Company & $\begin{array}{l}\text { Number of } \\
\text { employees }\end{array}$ & Location & Products \\
\hline $\begin{array}{l}\text { System } \\
\text { integrator }\end{array}$ & 425 & The Netherlands (East) & $\begin{array}{l}\text { Electro-hydraulic systems for operating } \\
\text { soft tops and retractable hard tops on } \\
\text { convertible cars as well as } \\
\text { opening/closing car trunks }\end{array}$ \\
\hline Supplier 1 & 200 & The Netherlands (South) & $\begin{array}{l}\text { Plastic precision parts and assembled } \\
\text { products for the automotive, medical } \\
\text { and pharmaceutical industry. } \\
\text { The company supplies the SI with } \\
\text { plastic moulding products. }\end{array}$ \\
\hline Supplier 2 & 55 & The Netherlands (East) & $\begin{array}{l}\text { Fine-mechanical parts for high-tech } \\
\text { industry; the company supplies parts } \\
\text { for the pump for opening the roof }\end{array}$ \\
\hline Supplier 3 & 160 & Germany (West) & $\begin{array}{l}\text { Cylinder-tubes for the automotive } \\
\text { industry }\end{array}$ \\
\hline
\end{tabular}




\section{Empirical findings}

This research started with engaging the involved companies in collaborative improvement projects, involving a process of diagnosing, fact-finding, implementation and evaluation of improvement actions on a dyadic level. The results of the improvement projects were presented and discussed in plenum to the other companies to evaluate and reflect on the process and progress of the collaborative improvement project. The findings of collaborative improvement projects in one dyadic relationship are discussed and evaluated in terms of applicability in other relationships. Throughout the process, explicit attention is paid to learning and development and how these can contribute to the company's knowledge and that of the whole network. Through this collaborative learning and improvement process, we are trying to build upon the knowledge of the members with regard to the contextual factors of collaborative improvement that play an important role, and the different roles played by the SI and their effect on the process and progress.

The companies have engaged themselves in CoI processes for a period of one-and-a-half years. It appeared that in the process of collaborative improvement, various contextual factors, endogenous as well as exogenous, played an important role in the process of collaborative improvement. Some of the better-known factors are sense of direction, commitment, (relative) power, and trust. In addition, however, the research also identified other significant factors, such as commercial reality, personal relationships, sense of urgency, and joint history (see Kaltoft et al., 2003). In the remainder of this section, we will present and discuss some of the empirical findings from the perspective of the SI based on the four mechanisms: scope, scale, skill and value, and social networking.

\subsection{Scope}

Companies are motivated to do certain things. This determines the scope of the social system. However, within the process of CoI, companies are not only motivated to attain their own goals, but also, through improvement and collaboration within a network to improve and enhance the performance of the whole network. As such, a shared and mutually understood vision is an important prerequisite for participating companies to fully exploit the opportunities within the relationship.

Initially, there was no mutual understanding of the concept of CoI. The companies lacked a shared vision on $\mathrm{CoI}$ and a sense of direction. The direction given for improvement activities between the SI and the suppliers were initiated and started based on a performance measurement tool, which is used by the SI to assess its suppliers with regard to cost, quality and delivery performance. The findings from a case study, as part of this research (see Middel et al., 2005b), indicated that many improvement activities actually were ad hoc, problem-driven improvement projects, rather than collaborative, structural and proactive improvement processes. The activities were centred on product and process problems and driven by the supplier-assessment of the SI with regard to cost, quality and delivery (Middel et al., 2005b). The suppliers' initial expectation was that the CoI project involved just another way of imposing cost reductions and other improvements. This affected the level of openness between the companies and resulted in political behaviour of the suppliers towards the SI. They waited for initiatives from the SI and did not show any sense of urgency. In the beginning of the project, the SI had put a 
lot of emphasis in explaining and discussing their vision and sense of direction with regard to collaborative improvement. This appeared to be necessary to overcome the political behaviour shown by the suppliers at the beginning of the project.

The approach that has been chosen towards engaging companies in collaborative improvement processes was a so-called laissez-faire approach (Kaltoft et al., 2003). The philosophy behind this approach is that collaboration and improvement in a network of companies are characterised by interdependence, shared goals and vision, trust, commitment, joint work and activities. Collaborative improvement initiatives should be initiated and selected by the whole group based on immediate practical problems or improvement opportunities. This approach was chosen by the SI in order to enable the participants/suppliers to discover and become aware of the concept and the possible benefits of collaborative improvement.

However, after a few months, hardly any improvement projects had been started between the companies. Although the companies supported the adopted approach, it did not lead to the required results with regard to collaborative improvement. The companies were not able to hold on to the enthusiasm and translate this enthusiasm into activities within the companies. Therefore, the SI decided to change the approach towards a more active and directive role of the lead company. The more active and directive role appeared to be important for the process and progress of the CoI initiatives in the Dutch setting. More improvement initiatives were identified and selected, more CoI meetings took place, and all companies participated more actively (see also Kaltoft et al., 2004). The leader's role that the SI fulfilled was necessary in terms of creating momentum and speeding up the CoI initiatives.

\subsection{Scale}

Companies are striving for optimisation of the situation in terms of financial capital (money). Companies are increasingly linking internal processes with external suppliers and customers, and the overall performance of the network is the result of the interaction between, and the integration of, inter-company processes (Cagliano, 2000).

Over a period of one-and-a-half years, five CoI initiatives between the SI and the suppliers were started in the different functional areas, such as quality, (change) order management, and manufacturing. The CoI initiatives were multi-disciplinary and required the involvement of different functional departments from all the companies, such as purchasing, engineering, sales, quality, and production. An overview of the CoI initiatives and the operational and learning outcomes is presented in Table 3.

The companies within the client system focused on real day-to-day issues and concerns that have been identified by them. Whereas the companies, initially, reacted and tended to focus CoI initiatives on problems, they recognised that they could concentrate also on more creative and proactive opportunities for improvement. As the process of CoI unfolded over time, the companies learned that CoI is not additional to daily activities, but an integral part of daily operational activities in and between the companies (Middel et al., 2005a).

As the companies engaged themselves in $\mathrm{CoI}$ initiatives, explicit attention was given to the diffusion of knowledge, experiences and lessons learned. Through facilitation and an active role in improvement and learning process, the SI enabled the companies to keep learning at the forefront of the agenda. Through presentation at meetings, feedback by 
other participants, factory tours and coaching, a learning environment was created as part of the collaborative improvement process. The learning environment provided a setting of reflection and evaluation with a high degree of openness and trust. This allowed the companies to learn from inter-organisational improvement processes and apply the created knowledge in their current work practices and in the management of collaborative (improvement) processes.

Table 3 CoI initiatives and their outcomes

\begin{tabular}{|c|c|c|c|}
\hline Relationship & $\begin{array}{l}\text { Collaborative } \\
\text { improvement initiative }\end{array}$ & Operational outcomes & Learning outcomes \\
\hline SI - Supplier 1 & $\begin{array}{l}\text { Redesign of a product, } \\
\text { which caused severe } \\
\text { problems during } \\
\text { malfunction in the } \\
\text { system of the SI }\end{array}$ & $\begin{array}{l}\text { Cost reduction and } \\
\text { increase of the quality } \\
\text { of the product. The } \\
\text { supplier was able to } \\
\text { reduce internal scrape } \\
\text { rate by } 33 \%\end{array}$ & $\begin{array}{l}\text { Increased awareness of the } \\
\text { need to communicate and } \\
\text { share information more } \\
\text { regularly. Closer } \\
\text { collaboration is necessary } \\
\text { to overcome problems. }\end{array}$ \\
\hline SI - Supplier 1 & $\begin{array}{l}\text { Proposal to produce an } \\
\text { existing product of the } \\
\text { SI of aluminium in } \\
\text { plastic }\end{array}$ & $\begin{array}{l}\text { Expected outcomes } \\
\text { are } 50 \% \text { cost reduction } \\
\text { for the SI and increase } \\
\text { in Sale for the supplier }\end{array}$ & $\begin{array}{l}\text { The inducement for } \\
\text { improvement is not always } \\
\text { a practical problem but } \\
\text { can also be more creative } \\
\text { and pro-active. }\end{array}$ \\
\hline SI - Supplier 2 & Cleanliness of products & $\begin{array}{l}\text { Increase in sales from } \\
\text { SI to supplier. } \\
\text { Reduction of reject } \\
\text { rate by SI }\end{array}$ & $\begin{array}{l}\text { Need for project planning. } \\
\text { Importance of information } \\
\text { sharing between the } \\
\text { companies. }\end{array}$ \\
\hline SI - Supplier 3 & $\begin{array}{l}\text { Information and } \\
\text { communication on } \\
\text { specifications of } \\
\text { products }\end{array}$ & NA & $\begin{array}{l}\text { Increased information } \\
\text { exchange and awareness } \\
\text { of need for improving } \\
\text { communication. }\end{array}$ \\
\hline SI - Supplier 3 & $\begin{array}{l}\text { Analyse and evaluate a } \\
\text { change in tooling } \\
\text { concept by the supplier }\end{array}$ & NA & $\begin{array}{l}\text { Increased insight in } \\
\text { organisational structure } \\
\text { and communication flows } \\
\text { on both sides. }\end{array}$ \\
\hline
\end{tabular}

Source: $\quad$ Middel et al. (2006)

\subsection{Skill and Value}

The research allowed insight into the process of collaborative improvement and to develop a better understanding of how companies can learn to collaborate on improvement issues and jointly improve their operations.

Throughout the process, the SI has put a lot of emphasis on the fact that collaborative improvement is not additional to daily activities, but an integral part of daily operational activities in and between the companies. There has been a strong advocacy from the side of the SI with regard to the 'skills and values' of CoI (see also Table 1), and through that to build upon the knowledge of the participating companies with regard to collaborative improvement. A shared belief in the value of small improvements and the creative potential of actors is an important prerequisite for CI and CoI (see also Caffyn, 1998). 
Assessments were used to trigger a dialogue between the companies involved, and to help develop a deeper understanding of the fundamental principles of the CoI and an increased motivation to participate in subsequent improvement activities (Middel et al., 2005a). Next to that, the CoI assessments measured the maturity of the companies with regard to CoI based on five behaviours:

1 guidance by shared improvement and collaboration values

2 usage of long-term goals and objectives to focus, prioritise and organise CoI activities

3 proactive participation in $\mathrm{CoI}$ and capturing and deploying the learning

4 participation in implementing and facilitating improvement projects across the border of the inter-company operations

5 constant evaluation of $\mathrm{CoI}$ projects to ensure that the outcomes are used to improve and monitor the CoI system.

At the start of this research, the companies scored particularly low on capturing and deploying learning from the CoI process and constantly evaluating the CoI projects (Middel et al., 2005a). Prior to the research, the companies were not used to stepping back and re-framing, and because of operational priorities within the companies, reflection and evaluation as part of collaborative improvement was not performed. Capturing knowledge from each improvement initiative can reduce the actions required in future initiatives and through that, others can learn from this knowledge repository (both in and between companies). By focusing on and paying explicit attention to reflection and evaluation from the side of the SI and the progress and process of CoI, the situation improved gradually over time, showing an increase in the score of the CoI maturity assessment on all five behaviours.

\subsection{Social networking}

Through interaction, companies integrate processes with others (social networking) in order to improve the performance, maintain and develop relationships, learn and build competences towards CoI. Within a relationship, people interact within a relationship with each other on different levels, both internally as externally, to affect the process, progress, expectations and outcomes of a relationship.

The companies within this research tend to focus the collaborative improvement projects on problems that had been encountered within the relationship in the areas of cost, quality and delivery. However, collaborative improvement activities can also concentrate on 'creative' improvements that are not related to problems but provide the companies with the similar benefits and develop the relationship. The SI has, and should pay explicit attention to fully explore and exploit the improvement potential within the inter-organisational relationships. Through communication and knowledge/information exchange, a setting should be created in which both reactive solutions and creative opportunities are stimulated and triggered. Within this research, the companies were not only committed to take the necessary strategic and operational steps to engage in $\mathrm{CoI}$ initiatives, but also committed to learning. During each meeting, presentations were given with regard to the progress and process of an improvement initiative, which were discussed and reflected on in plenum at the meetings. Explicit attention was given to the 
diffusion of knowledge, experiences and lessons learned as part of the collaborative improvement initiatives. As such, the companies within the network were able to combine resources and activities with each other and develop knowledge and create an insight into the concept and benefits of CoI.

Within the process of CoI, it appeared that internal networking is at least as important as external networking. The progress of $\mathrm{CoI}$ initiatives and ultimately, the results of the project, are to a large degree influenced by the intra-organisational processes. An example out of practice is the biased attention of a representative of the SI on cost reduction, which was conflicting with the expressed and mutually agreed vision with regard to CoI. This had led to a situation where the supplier was not willing to share experiences, knowledge and learning moments with regard to product and improvement process with the system integrator. Because of a lack of internal interaction (communication and information exchange) among departments within an organisation and lack of integrating internal processes, collaborative improvement projects were negatively influenced in terms of project process and progress.

\section{Discussion}

Continuous Improvement and continuous cost reduction are integrated and explicit in the policy of the SI. As such, the SI looks for strategically significant partners who fully support the policy and practices of the SI. The selection process was based on this notion and the SI aimed at establishing close collaboration and long-term partnership with the selected suppliers. Within this close collaboration, companies need to focus on collaborative efforts and initiatives to continuously improve and change the current processes and work practices for the benefit of both.

In order to support and facilitate $\mathrm{CoI}$ initiatives, a programme was designed and built around a structure of regular workshops. Here, the participating companies would meet in a group, discuss and reflect on the progress of the CoI initiative and follow up on the learning in the day-to-day enactment of attempted solutions to the collaborative problem. An AR approach was selected, which allowed the researchers to interact with the companies as the companies engaged themselves in the process of CoI. The role of the action researcher was to facilitate and stimulate evaluation and reflection of the CoI process, acquire an EME perspective and contribute to the actionable knowledge of the CoI process. The approach allowed the researcher access to rich and detailed information and yielded insights into the management and organisation of CoI.

The empirical findings presented in this paper indicate that the process of CoI is fraught with difficulties related to intra- and inter-organisational change issue and work practices. As insight and understanding by the SI and the other participants developed over time, several issues from the perspective of the SI can be highlighted to lead to successfully managing and organising CoI:

- Develop an understanding of the position of the other suppliers and create a sense of direction within the network.

- Create a learning environment in which companies can and do, openly communicate and share information. 
- Facilitate the process of $\mathrm{CoI}$ initiatives and learning through different interventions, such as presentations, feedback, factory tours, and coaching.

- Show an active and committed attitude towards CoI to keep momentum and progress in the $\mathrm{CoI}$ initiatives and create a sense of urgency throughout the whole process.

- Recognise that internal networking is at least as important as external networking in the process and progress of CoI.

- Develop all four mechanisms of scope, scale, skill and social networking sufficiently in order for the network to last and avoid a biased attention on one of the mechanisms.

\section{Conclusions}

Continuous improvement is a consolidated concept in managerial theory and practice and is considered vital in today's business. But a strong limitation of the literature of CI is the focus on the context of the stand-alone company. As competition is changing, we need to transfer and apply the concept and practical elements of CI to the inter-organisational setting. In order to be able to effectively organise and manage the process of continuous improvement in a network of organisations, we need to gain insight and develop understanding and knowledge on the process of CoI.

The network model of actors has provided us with a framework to explain and understand some of the dynamics and interaction within the process of CoI between the SI and their suppliers. The SI can use the mechanisms more or less successfully to develop positions in relation to the suppliers, and consequently to influence the outcomes of the CoI initiatives for the whole network. On the other hand, a biased attention to one of the mechanisms will negatively influence the process and progress of CoI.

The action research approach has been efficient and effective for both the researchers and companies (Middel et al., 2006). From the perspective of the researchers, it has allowed in-depth insight into, and development of an understanding of, the process of collaborative improvement in order to generate actionable knowledge. From the perspective of the companies, it has allowed the companies to experience the relevance of reflection and evaluation upon activities performed as part of inter-organisational work practices.

Additional challenges and suggestions for future research are as follows:

- In this research we found that internal networking is at least as important as external networking in the process of CoI, but what is the affect of internal networking on the process and progress of CoI? More research is required on the influence of internal networking on the outcomes of CoI.

- Is has been stated that the four mechanisms of the network model should be developed sufficiently in order for the network to last, but is there a specific level which is required for CoI to thrive? Does a higher level of development of the four mechanism yield more and better outcomes than lower levels? Is there a relationship between the level of development of the four mechanisms in a network and the outcomes of the CoI process. 
- In creating an insight and in developing knowledge of the management and organisation of CoI processes, next to qualitative research, more quantitative research is required to investigate the factors at play and the interrelationship among these factors.

\section{References}

Aldrich, H. and Zimmer, C. (1986) 'Entrepreneurship through social networks', in D. Sexton and R.W. Smilor (Eds.) The Art and Science of Entrepreneurship, New York: Ballinger Publishing, pp.3-23.

Bessant, J. and Caffyn, S. (1997) 'High-involvement innovation through continuous improvement', International Journal of Technology Management, Vol. 14, No. 1, pp.7-28.

Boer, H. and Gertsen, F. (2003) 'From continuous improvement to continuous innovation, a (retro)(per)spective', International Journal of Technology Management, Vol. 26, No. 8, pp.805-827.

Boer, H., Berger, A., Chapman, R. and Gertsen, F. (Eds.) (2000) CI Changes: from Suggestion Box to Organisational Learning. Continuous Improvement in Europe and Australia, Aldershot: Ashgate Publishing.

Burns, T. and Stalker, G.M. (1961) The Management of Innovation, London: Pergamon.

Burt, R.S. (1992) Structural Holes: The Social Structure of Competition, Cambridge, MA: Harvard University Press.

Caffyn, S.J. (1998) 'The scope for application of continuous improvement to the process of new product development', PhD Thesis, University of Brighton.

Cagliano, R. (2000) 'Integration mechanisms of inter-company processes', Proceedings of the First World Conference of Production and Operations Management (on CD-Rom).

Cagliano, R., Caniato, F., Corso, M. and Spina, G. (2005) 'Implementing collaborative Improvement: lessons from an action research process', International Journal of Production Planning and Control, Vol. 16, No. 4, pp.345-355.

Coghlan, D. and Brannick, T. (2005) Doing Action Research in Your Own Organization, 2nd ed., London: Sage.

Coughlan, P. and Coghlan, D. (2002) 'Action research for operations management', International Journal of Operation and Production Management, Vol. 22, No. 2, pp.220-240.

Coughlan, P., Coghlan, D. and Brennan, L. (2004) 'Organizing for research and action: implementing action researcher networks', Systemic Practice and Action Research, Vol. 17, No. 1, pp.37-49.

De Lange-Ros, D.J. (1999) 'Continuous improvement in teams. The (mis)fit between improvement and operational activities of improvement teams', PhD Thesis, Enschede: Print Partner Ipskamp.

Doz, Y.L., Hamel, G. and Prahalad, C.K. (1989) 'Collaborate with your competitors and win', Harvard Business Review, Vol. 67, No. 1, pp.133-139.

Eden, C. and Huxman, C. (1996) 'Action research for the study of organizations', in S. Clegg, C. Hardy and W. Nord (Eds.) Handbook of Organization Studies, London: Sage Publications, pp. 526-542.

Frohlich, M.T. and Westbrook, R. (2001) 'Arcs of integration: an international study of supply chain strategies', Journal of Operations Management, Vol. 19, pp.185-200.

Granovetter, M. (1992) 'Problems of explanation in economic sociology', in N. Nohria and R.G. Eccles (Eds.) Handbook of Economic Sociology, Boston: Princeton University Press, pp.453-475. 
Groen, A.J., De Weerd-Nederhof, P.C., Kerssens-Van Drongelen, I.C., Badoux, R.A.J. and Olthuis, G.P.H. (2002) 'Creating and justifying research and development value: scope, scale, skill and social networking of R\&D', Creativity and Innovation Management, Vol. 11, No. 1, pp.2-15.

Håkansson, H. (1987) Industrial Technological Development: A Network Approach, London: Croom Helm.

Håkansson, H. and Snehota, I. (1995) Networks in Technological Development, London: Routledge.

Imai, M. (1986) Kaizen. The Key to Japan's Competitive Success, London: McGraw-Hill.

Kaltoft, R., Boer, H., Corso, M., Gertsen, F., Gieskes, J., Middel, H.G.A. and Nielsen, J.S. (2003) 'Factors affecting the development of collaborative improvement with strategic suppliers', in G. Spina (Ed.) Proceedings of the EUROMA and POMS Conference 2003 - The Challenges of Integrating Research and Practice, Vol. 3, pp.601-610.

Lamming, R. (1993) Beyond Partnership, UK: Prentice Hall.

Lau, F. (1999) 'Toward a framework for action research in information systems studies', Information Technology and People, Vol. 12, No. 2, pp.148-175.

Middel, H.G.A. and McNichols, T. (2006) 'Cultivating collaborative improvement: an action learning approach', International Journal of Learning and Change, Vol. 1, No. 2, pp.229-245.

Middel, H.G.A., Boer, H. and Fisscher, O.A.M. (2005a) 'Collaborative Improvement: what do we know? Where do we need to go?', Proceedings of the 6th International CINet Conference, pp.456-467 (on CD-Rom).

Middel, H.G.A., Gieskes, J.F.B. and Fisscher, O.A.M. (2005b) 'Driving collaborative improvement processes', International Journal of Production Planning and Control, Vol. 16, No. 4, pp.368-377.

Middel, R., Coghlan, D., Coughlan, P. Brennan, L. and McNichols, T. (2006) 'Action research in collaborative improvement', International Journal of Technology Management, Vol. 33, No. 1, pp.67-91.

Mohr, J. and Spekman, R. (1994) 'Characteristics of partnership success: partnership attributes, communication behavior, and conflict resolution techniques', Strategic Management Journal, Vol. 15, No. 2, pp.135-152.

Nonaka, I. and Takeuchi, H. (1995) 'The knowledge creating company', Harvard Business Review, November-December, pp.96-104.

Rijnders, S. (2002) 'Four routes to continuous improvement, an empirical typology of CI implementation processes', PhD Thesis, Enschede: Twente University Press.

Ring, P.S. and Van de Ven, A.H. (1992) 'Structuring cooperative relationships between companies', Strategic Management Journal, Vol. 13, No. 7, pp.483-498.

Robinson, A. (1991) Continuous Improvement in Operations, A Systemic Approach to Waste Reduction, Cambridge, MA: Productivity Press.

Sobrero, M. and Schrader, S. (1998) 'Structuring inter-firm relationships: a meta-analytic approach', Organization Studies, Vol. 4, No. 19, pp.585-616.

Westbrook, R. (1995) 'Action research: a new paradigm for research in production and operations management', International Journal of Operations and Production Management, Vol. 15, No. 12 , pp.6-20. 